\title{
Shakespeare, Kabbalah e a responsabilidade sobre o mistério das coisas
}

\section{Shakespeare, Kabbalah and the responsibility about the mystery of the things}

Carlos Roberto Bueno Ferreira ${ }^{1}$, Claudio Levitan²

1 Doutorando em Filosofia pela Pontifícia Universidade Católica do Rio Grande do Sul. E-mail: crbuenoferreira@gmail.com Mestre em MPhil of Philosophy - Newcastle University (1981), Inglaterra, e graduado na Faculdade de Arquitetura pela Universidade Federal do Rio Grande do Sul (1974). E-mail: claudiolevitan@gmail.com
RESUMO: É possível traçar um paralelo entre a técnica literária de Shakespeare e os ensinamentos do misticismo judaico conhecido como Kabbalah? Esse é o foco deste ensaio. A arte de Shakespeare permite interpretações em diversos níveis de profundidade. O homem retratado por Shakespeare é um ser atormentado e dividido entre a luta contra suas próprias paixões e a busca de um significado maior para sua existência, atrelada à reconexão com uma realidade superior. 0 presente trabalho tenta apontar os possíveis paralelos entre a tradição mística da Kabbalah e algumas obras da maturidade de Shakespeare, na esperança de extrair as semelhanças entre as peças do dramaturgo inglês e modo de interpretação dos textos sagrados conforme certos simbolismos da Kabbalah, relativos a uma jornada de purificação espiritual. Nesse sentido, buscamos apontar que 0 conteúdo místico é parte fundamental da obra shakespeariana. Contudo, não se trata de exoterismo leviano e desmedido, mas um trabalho criterioso que considera uma genuína responsabilidade sobre o mistério das coisas.

Palavras-chave: Shakespeare; Kabbalah; Misticismo Judaico; Hamlet

ABSTRACT: Can we draw a parallel between the literary technique of Shakespeare and the teachings of Jewish mysticism known as Kabbalah? This is the focus of this essay. Shakespeare's art allows interpretations in different depth levels. The man portrayed by Shakespeare is a being tormented and torn between the fight against their own passions and the search for greater meaning to their existence, linked to the reconnection to a higher reality. This paper attempts to point out the possible parallels between the mystical tradition of Kabbalah and some works of Shakespeare's maturity, hoping to draw the similarities between the pieces of the English playwright and the mode of interpretation of sacred texts and certain symbolisms of Kabbalah, relating to a journey of spiritual purification. In this sense, we try to point out that the mystical content is a key part of the Shakespearean work. However, this is not frivolous and excessive exotericism but a careful work that considers a genuine responsibility about the mystery of things. KEYworDS: Shakespeare; Kabbalah; Jewish Mysticism; Hamlet 


\section{Introdução}

W

illiam Shakespeare é frequentemente enaltecido como um profundo conhecedor da natureza humana. Suas peças possuem um apelo quase místico que magnetiza o leitor. Contudo, essa atração incontrolável não decorre simplesmente da narração de histórias que exprimem fidedignamente as virtudes e vicissitudes de uma determinada sociedade em seu tempo. O sentimento de conexão inspirado pelos textos shakespearianos nos liga diretamente aos dilemas morais (e espirituais) que decorrem das jornadas de transformação de seus respectivos personagens.

O fato é que há algo em Shakespeare que está além de uma observação superficial. Poderia a Kabbalah, a antiga tradição mística judaica, ter parte nessa inexplicável atração despertada pelas peças do dramaturgo inglês? Essa é a relação que pretendemos desvendar neste ensaio.

\section{Shakespeare e o Espírito de seu tempo}

Shakespeare nasceu em 23 de abril de 1564, em Stratford-upon-Avon e faleceu no ano de 1616, no mesmo dia e local de seu nascimento. São atribuídos à sua autoria 154 sonetos e 38 peças.

Existem teorias que defendem as mais variadas origens para a produção atribuída ao dramaturgo inglês. Algumas dessas versões sustentam que a nobreza não tolerava ter sua reputação atrelada à arte popular e, por isso, os nobres que se aventuravam no mundo da literatura procuravam as companhias de teatro para que, mantendo o anonimato, representassem suas peças. Outra teoria é a de que Francis Bacon seria o verdadeiro autor por trás das obras shakespearianas. Isso porque não se acreditava que alguém como Shakespeare, sem formação acadêmica, poderia ter sido capaz de tamanha riqueza literária.
Este é o ponto pelo qual podemos começar. Outros autores dessa mesma geração que possuíam a "devida" formação literária, como Marlowe e o próprio Bacon, tinham produções muito diversas da do Bardo de Avon, e com focos muito mais renascentistas.

Com efeito, Shakespeare viveu durante o período histórico do renascimento europeu (séc. XIV ao XVII), no qual os valores mais fortemente cultivados eram o humanismo e o antropocentrismo. Entretanto, suas peças parecem remeter a um momento diverso, ainda como arte medieval, na qual o individual somente existe como uma extensão do universal. Talvez tenha sido justamente a falta da formação acadêmica que tenha lhe permitido investir suas forças em uma arte que estava fora de seu tempo.

O homem retratado por Shakespeare é um ser atormentado e dividido entre a luta contra suas próprias paixões e a busca de um significado maior para sua existência, atrelada à reconexão com uma realidade superior. Assim, situa-se muito mais próximo da representação medieval (da existência humana como um fardo) que do homem da renascença, autônomo e racional.

Podemos apontar certas passagens em suas peças que corroboram uma visão menos antropocêntrica e mais mística da humanidade, como em Hamlet (Ato V, Cena 2): "A vida humana não dura mais do que a contagem de um” (SHAKESPEARE, 2008b, p. 598); ou em Rei Lear (Ato IV, Cena 1 e 3): “O que para os garotos são as moscas, nós somos para os deuses: matam-nos por brinquedo" (SHAKESPEARE, 2008b, p. 701) e "são os astros, os astros lá em cima nossas condições” (SHAKESPEARE, 2008b, p. 704).

Martin Lings, ao analisar a obra de Shakespeare, aborda a arte medieval como sendo, acima de tudo, um retrato do Espírito. Uma janela que se abre do particular para o universal e que, mesmo que produzida em um determinado tempo e lugar, passa a existir independentemente, sempre atual e não localizada. Conforme ilustra Schuon: 
Quando estamos diante de uma catedral românica ou gótica, nos sentimos no centro do mundo; estando em frente a uma igreja renascentista, barroca ou rococó, nos sentimos apenas na Europa (SCHUON 1984, p. 61).

A arte renascentista, nesse contexto, careceria dessa abertura para o universal, ficando adstrita ao seu próprio tempo. Isso poderia advir de sua perspectiva limitada pela moldura humanista, já que, para Lings, "o humanismo é a revolta da razão contra o intelecto, pois considera o homem e os outros objetos terrenos inteiramente por si mesmos, como se não houvesse nada além deles" (LINGS, 2004, p. 17).

Ainda que o objetivo deste ensaio não seja desmerecer a arte renascentista, não há como deixar de considerar a crítica de Lings, porquanto a arte que parte de uma perspectiva puramente antropocêntrica tende a ser uma representação que depende muito da beleza estética superficial (literal). Da mesma forma, a arte excessivamente ligada à perspectiva do ser humano possui maiores dificuldades de manter-se atraente se tomada fora de seu tempo. Por fim, é mais fácil conceber que uma abordagem que considere uma ordem cosmológica mais ampla que o próprio homem seja mais fidedigna em relação à representação da verdadeira natureza das coisas.

A representação da Criação por Michelangelo, por exemplo, trata Adão não como um símbolo, mas como uma realidade. Assim, não há uma representação do homem à imagem de Deus, mas sim uma figuração de Deus à imagem do homem.

Shakespeare nasceu três meses após a morte de Michelangelo, foi contemporâneo de Giordano Bruno, viveu na época de ouro da Kabbalah, no tempo de Isaac Lúria, talvez o maior kabbalista de todos os tempos, responsável por desvelar um sistema místico de transmigração e superfetação das almas, bem como inúmeras representações e interpretações sobre a verdadeira criação de todas as coisas. Não restam dúvidas de que foi uma época de grande iluminação, contudo, às vezes a melhor maneira de se revelar a luz é justamente identificar o limite da sombra ao seu redor.

A obra de Shakespeare é atual ainda hoje exatamente porque retrata a conexão do homem com o universal e, para fazê-lo, não basta simplesmente uma boa história e conhecimento gramatical.

Martin Lings aproxima a abordagem assumida nas peças shakespearianas de obras ditas esotéricas. Aqui, cumpre diferenciar as obras esotéricas (as quais remetem para além da salvação, uma espécie de santificação, uma experiência que parte do indivíduo em busca de uma reconexão, uma religação) das obras exotéricas ou ocultistas (nas quais a salvação é um ideal, não uma imposição). 0 maior exemplo de obra esotérica é a Divina Comédia de Dante. Nela, está em jogo a recuperação do status que foi perdido com "A Queda do Homem".

A maior parte das peças de Shakespeare, em especial aquelas produzidas na maturidade do autor (1600 a 1613), podem ser interpretadas como representações de uma via espiritual. Jornadas de purificação, por vezes mais bem sucedidas e por vezes fracassadas, tanto das personagens dos textos como do leitor que as acompanha.

Shakespeare e Dante, durante suas vidas, pertenceram a ordens místicas que pregavam justamente essa jornada pessoal de purificação. Segundo Lings, Dante era membro da Ordem do Templo, enquanto Shakespeare teria sido membro da Ordem Rosacruz, uma sociedade de conhecimentos ocultistas que se intitula herdeira das tradições místicas que remontam à alquimia medieval, ao gnosticismo, ao ocultismo, ao hermetismo no antigo Egito, ao neoplatonismo e à Kabbalah. Assim, é razoável afirmar que Shakespeare, ao atingir sua maturidade literária, estivesse familiarizado com esses diversos conhecimentos, alguns realmente esotéricos e outros apenas ocultistas.

Dante apontava que os textos devem ser entendidos e expostos principalmente de acordo com quatro sentidos: o literal, o alegórico, o moral 
e o anagógico. Mais precisamente, o sentido literal deve servir como um véu que encobre os demais níveis de entendimento.

Shakespeare certamente conhecia essa estratificação de sentidos dentro de um mesmo texto. As histórias literais e as tramas das obras shakespearianas são relativamente simples e raramente são a estrela do espetáculo. Em sua grande maioria as peças são versões de acontecimentos históricos ou dilemas sociais da nobreza de sua época. Os momentos mais sublimes das representações dramáticas shakespearianas se dão em uma profundidade diferente. O solilóquio "ser ou não ser" de Hamlet, o enlouquecimento do Rei Lear e o pesar de Macbeth em face do seu destino inexorável representam uma descida às profundezas dos personagens, um convite para que participemos de suas respectivas jornadas de salvação (tanto a salvação literal como a salvação espiritual).

Aliás, isso remete a um fato curioso. Das 38 peças atribuídas a Shakespeare, apenas uma delas é reconhecidamente uma história original: a comédia $A$ tempestade. As demais obras, que não os dramas históricos, são narrativas extraídas do folclore de diversos locais da Europa. Hamelt, por exemplo, a peça mais renomada de Shakespeare, é reconhecidamente baseada na lenda nórdica de Amleto, preservada no século XIII pelo cronista Saxo Grammaticus em seu Gesta Danorum, e também toma elementos de uma suposta peça do teatro isabelino conhecida como Ur-Hamlet.

Tal postura era comum na época de Shakespeare. Ao reciclar histórias antigas e basear as obras no trabalho de outros escritores, as companhias de teatro garantiam mais agilidade no lançamento das novas peças. Ademais, a estratégia de basear as representações dramáticas em histórias já populares se mostrou muito eficaz para atrair grandes públicos.

Shakespeare tinha plena consciência de tudo isso e convenientemente aproveitou essa oportunidade para relegar o sentido literal de sua obra ao seu devido lugar: o de véu que encobre os verdadeiros sentidos: alegórico, moral e anagógico.

Se até agora não pudemos traçar uma ligação direta entre a obra de Shakespeare e a Kabbalah, aqui resta clara a conexão. A Kabbalah tem sido descrita como um conjunto de conhecimentos místicos que remontam ao primeiro homem, Adam HaRishom (Adão). Os livros mais estudados pelos cabalistas, como o Sêfer Yetzirah e o Sêfer HaZohar, são, na verdade, estudos em níveis de exegese da Torah, a Bíblia.

De acordo com o Zohar, existem quatro níveis de interpretação do texto sagrado: Peshat, Remez, Drash e Sod, os quais, em hebraico, conformam o acrônimo PaRDeS (פרדס). O primeiro nível ou Peshat (פשט) é o literal ou histórico; o segundo, Remez (רמז), é o alegórico e simbólico; o terceiro, Drash (דרש), é o exegético e hermenêutico; e o quarto, Sod (סוד), é o nível secreto, o sentido esotérico, repassado de mestre a discípulo.

O próprio Dante faz referência expressa a esse conhecimento e ilustra com a interpretação do êxodo dos judeus do Egito para a Terra prometida, apontando que, além do sentido literal e histórico, essa jornada significa o êxodo da alma desde o estado do pecado original até a santificação.

Admitindo que a obra de Shakespeare foi concebida com mais de um nível de interpretação em mente, percebemos que a história literal serve de moldura fática para que se conte uma outra história muito mais profunda, que reflete uma verdadeira transformação do Espírito. Podemos classificar o trabalho do Bardo de Avon como sendo arte sagrada (e não no sentido tradicional de liturgia religiosa, mas sim pela semelhança extralitúrgica com o Espírito universal e pela busca constante da sophia perennis).

Propomo-nos, então a apreciar alguns dos textos da maturidade de Shakespeare, apontando possíveis referências aos diversos níveis de interpretação que restam presentes nas obras deste período da produção do dramaturgo inglês. É inevitável que encontremos paralelos com a Kabbalah, 
mesmo que de forma indireta, pois, como já explicamos, muitas das correntes esotéricas que se fizeram presentes na época de Shakespeare eram herdeiras (próximas ou distantes) dos conhecimentos do antigo misticismo judaico.

\section{A Obra da maturidade}

Hamlet, em linhas gerais, e considerando a literalidade da trama, conta a história de como o príncipe da Dinamarca, Hamlet, reage em face da morte de seu pai, o rei, envenenado por Cláudio, seu tio, irmão do rei, que em seguida tomou o trono, casando-se com a rainha Gertrudes, sua mãe. A interpretação mais simples dessa obra é a de que se trata de uma história de traição, incesto, corrupção e, sobretudo, vingança, na qual Hamlet tenta restabelecer a ordem do reino da Dinamarca, uma vez que o trono foi usurpado por seu tio Cláudio.

Se quisermos, contudo, uma intepretação mais aprofundada, podemos começar pelas palavras do próprio príncipe, no Ato III, Cena 1: “A virtude não pode enxertar-se em nosso velho tronco, sem que deste não remanesça algum travo" (SHAKESPEARE, 2008b, p. 573). Observando essa passagem, podemos notar que a jornada de Hamlet não é somente uma questão de vingança, mas um dilema entre seguir ou não o caminho da justiça e da correção do espírito, deixando o cheiro do velho tronco para trás.

O caminho, entretanto, é árduo e a simples inoculação de algumas virtudes superficiais não será suficiente. $O$ que é exigido do príncipe não é nada menos do que a perfeição, ou seja, a completa reversão da Queda do Homem.

Aqui temos um paralelo com a iniciação nos mistérios esotéricos (os quais não eram novidade para Shakespeare) como o conhecimento da Kabbalah. A iniciação não é senão a inoculação da natureza primordial do homem no velho tronco de sua natureza decaída. Daí a possibilidade para o neófito de assumir o compromisso de proteger e nutrir esse broto, para que ele possa, com o tempo, suplantar o velho e fétido tronco. Para um homem de entendimento, o reconhecimento do estado de homem decaído é um estado de desonra.

Assim é que a arte sagrada desvela os seus diversos níveis de entendimento, como uma pedra jogada na água que gera círculos concêntricos que se espalham em repercussões ilimitadas. Observando por este prisma, a obra de Shakespeare abre-se para um significado mais profundo e temos a frequente impressão de que ela transmite muito mais do que aparenta.

No sentido literal da história, aceitamos que a vingança é o caminho natural e correto a seguir. A interpretação alegórica, que decorre da revelação do espectro do antigo rei, traz a dúvida e a angústia de não se entender a mensagem por completo, como se estivessem faltando peças em um quebracabeça. Somente uma interpretação mais profunda parece capaz de fazer emergir aquilo que não foi revelado, o que demanda uma jornada paralela de afastamento das próprias paixões (purificação) para que a figura possa desvelar-se plenamente.

Esse exercício de autocontrole é parte fundamental do processo de santificação. A preocupação com o próprio egoísmo é tema recorrente nas peças de Shakespeare, como podemos constatar na passagem em que Hamlet elogia Horácio (Hamlet, Ato III, Cena 2): “Mostra-me um homem liberto de suas paixões; pô-lo-ei no coração, no próprio coração do coração, tal como fiz contigo!" (SHAKESPEARE, 2008b, p. 575)

Também o leitor é convidado a participar dessa jornada de crescimento espiritual e, de acordo com sua capacidade de entendimento, embarca nessa gradual elevação da profundidade desde o sentido literal até o mais extasiante contato com o sentido esotérico máximo pretendido pelo autor da obra.

As relações entre personagens representam mais do que aparentam. Se tomarmos o conturbado sentimento de Hamlet por sua mãe podemos 
verificar que está presente o estigma da mulher culpada, que remonta a Eva. E, como Eva, ela representa a própria queda da alma humana, no seu aspecto passivo.

Na peça, a rainha é inocente do assassinato do rei. Hamlet, contudo, não se conforma que sua mãe tenha aceitado tão tranquilamente casar-se com seu tio Cláudio, homem que envenenou o rei. Nas palavras do príncipe: "Só se alegra com outro companheiro quem foi a causa do primeiro" (SHAKESPEARE, 2008b, p. 576). Decerto Gertrudes serve de espelho para a situação em que se encontra Hamlet. A indignação do príncipe é justamente por ela ter-se calado em face daquilo que ele, sabendo o que sabe, não pode se permitir aceitar passivamente. Trata-se, portanto, de uma projeção de suas próprias aflições, uma vez que o próprio príncipe mostra-se dividido entre agir e não agir, ser ou não ser, dormir ou não dormir, viver ou morrer.

O lugar da peça também não é senão uma desculpa para que Shakespeare possa apresentar o mundo no qual o ser humano encontra-se caído e corrompido por suas próprias paixões. Marcelo diz no Ato I, Cena 4: “Algo está a apodrecer na Dinamarca" (SHAKESPEARE, 2008b, p. 559). Podemos concluir que a Dinamarca é uma representação de toda a humanidade caída. Shakespeare trata o mundo dos mortos como um outro país, como vemos no solilóquio do Ato III, Cena 1: "se não por temer a morte - terra desconhecida de cujo âmbito jamais ninguém voltou" (SHAKESPEARE, 2008b, p. 572).

$\mathrm{O}$ medo, a dúvida e a falta de coragem podem levar à morte, mas aquele que trilha o caminho da santidade não pode temer nem mesmo a sua própria finitude. Nas palavras do próprio príncipe Hamlet em relação à atitude que se deve ter diante da morte: "o principal é estarmos preparados" (SHAKESPEARE, 2008b, p. 600). Tal tema é reincidente nas obras de Shakespeare. Em Rei Lear, Ato V, Cena 2, Gloucester lembra-nos que os "Precisamos mostrar-nos conformados com nossa vinda ao mundo e ao nos partirmos. Estarmos preparados é o que importa" (SHAKESPEARE, 2008b, p. 713).
Se tomarmos a missão que Hamlet tem à sua frente sob esse prisma, podemos compreender melhor por que ele encontra-se tão dividido. 0 solilóquio "ser ou não ser" revela na mesma medida a maturidade de Hamlet e sua hesitação em assumir o papel que se espera dele.

Com efeito, aquele que acredita que algo universal rege todas as outras coisas, incluindo a natureza humana, deve também acreditar que:

Há uma providência especial na queda de um pardal. Se é agora, não está para vir; se não está para vir, a hora é esta; e se esta é a hora, virá de qualquer modo. A prontidão é tudo. E como nenhum homem é senhor do que abandonará um dia, que importa abandoná-lo cedo ou tarde? Seja como for (Hamlet, Ato V, Cena 2 - SHAKESPEARE, 2008b, p. 600).

Na tradição mística é necessário que se acredite em algo superior que governe todas as outras coisas. Com efeito, é nítida a semelhança com o conhecimento kabbalístico de que nem um único talo de grama se movimenta aqui embaixo sem que um anjo comande-o a crescer. Na Kabbalah, a força da criação é representada por Ayn Sof, a raiz eternamente negativa. Trata-se de uma qualidade primordial, um registro de toda ordem do universo. Toda a criação somente teve lugar em razão de uma grande restrição inicial e tudo que existe até hoje é decorrência dessa vontade primordial. Os kabbalistas não buscam definições que possam dar conta de explicar o que significa essa raiz negativa, sequer é permitido que se pronuncie o seu nome verdadeiro.

Contudo, é comum tanto à obra de Shakespeare como à tradição da Kabbalah, que o candidato à jornada de purificação espiritual deva confiar na providência superior. O ditado hebraico "gam zu le tová" pode ser traduzido como "tudo que vem é pelo bem". Cumpre ressaltar, entretanto, que, a exemplo do que aflige o príncipe Hamlet, não se trata de uma postura de comodidade fatalista, que paralisa o sujeito em face da natureza determinista das coisas.

Na realidade, é justamente o exercício de conexão com a vontade superior que, ao mesmo tempo, revela o conhecimento necessário para que se possa 
compreender a causa primordial das coisas e liberta a alma para que possa fazer cumprir essa vontade sagrada. Não se trata, portanto, de determinismo, mas sim de uma ordem espiritual pré-estabelecida, a qual não permite meia adequação. Ou se está no paraíso ou se está no deserto.

O contato com esse conhecimento sagrado cobra o seu preço. Quanto menos preparado (purificado) o iniciado estiver para receber tal informação, mais graves podem ser as consequências. Nas obras de Shakespeare, o contato com a sabedoria espiritual é representado alegoricamente como uma forma de loucura. Faz bastante sentido, já que a espiritualidade, sob um ponto de vista mundano, é uma espécie de insanidade.

O melhor exemplo disso é a loucura de Lear. Em Rei Lear, Shakespeare narra a história de um rei idoso que resolve adiantar em vida a divisão do seu reino entre suas três filhas. Para calcular a partilha, pede às filhas que expressem a gratidão e o amor que sentem pelo pai. Goneril e Regan fazem discursos aduladores, em que afirmam que o amam mais do que qualquer coisa no mundo. Cordélia, por outro lado, contraria as expectativas do rei e afirma que o ama "como o dever me impõe, nem mais nem menos" (SHAKESPEARE, 2008b, p. 668). Irritado com essa resposta, Lear deserda-a e expulsa-a do reino, entregue sem dote ao rei da França. Uma reviravolta ocorre e, uma vez que suas filhas assumem o poder, elas expulsam o pai da própria casa. Ao fim da peça, ao reconhecer seus erros, Lear enlouquece e somente Cordélia se compadece da situação do pai.

Segundo Lings Lear baniu a harmonia e deixou seu reino à mercê da discórdia (representada por suas duas filhas Goneril e Regan). Ao trocar o três pelo dois, ele trocou a sabedoria espiritual pela sabedoria da Árvore do Conhecimento do Bem e do Mal. A sabedoria mundana estará no comando daqui em diante. Nessa peça, Cordélia e o Bobo são as representações do espírito e são suas ações que despertam em Lear a faísca para que comece sua jornada de purificação. Em uma cena memorável, o Bobo estende seu gorro de bobo da corte a Caio (que na verdade é o conde de Kent, homem que foi banido do reino por interceder por Cordélia):

Por quê? Por teres tomado partido de quem está fora da graça. Não senhor! Se não podes sorrir do lado que sopra o vento, então logo ficarás resfriado. Aqui está: pega e fica com o meu gorro. Por que este camarada [indicando Lear] baniu duas de suas próprias filhas e abençoou a terceira, contra a própria vontade; se o seguires precisará do meu gorro. (Rei Lear: Ato I, Cena 4 - SHAKESPEARE, 2008b, p. 676).

A loucura de Lear é uma alegoria que demonstra claramente sua jornada de purificação espiritual. No ato IV, cena 6 o conde de Gloucester reconhece o rei e pede para beijar sua mão. Lear responde "primeiro deixai que a limpe; cheira a mortalidade" (SHAKESPEARE, 2008b, p. 708).

Ora, somente pode distinguir o cheiro da mortalidade (e se sentir incomodado com ele) quem já teve contato com alguma espécie de purificação espiritual. Caso contrário, como poderia alguém que sempre viveu no deserto sentir perfume de flores?

Martin Lings considera que a alegoria da loucura possui o mesmo simbolismo, tanto no caso de Lear como no caso da loucura simulada de Hamlet. Defato, nos dois casos a loucura aponta algum grau de espiritualização, contudo, os tipos de loucura geram consequências diversas. No caso de Lear, o processo de santificação é mais genuíno. Lear aceita a sua loucura e prefere permanecer nela a voltar ao mundo que deixou para trás. Hamlet, por sua vez, se vale da loucura como artimanha que lhe permite certa vantagem em relação aos que não sabem do seu fingimento.

Cumpre ressaltar que a espiritualidade do místico é magnética para todas as almas que são forjadas do mesmo metal. A "loucura" de Hamlet gerou uma boa dose de tragédias, a começar pela morte de Ofélia, passando pela morte acidental de Polônio e culminou com a sua própria morte. Num mundo onde o chumbo é muito mais abundante que o ouro, uma alma que 
reluz possui pouco poder magnético. É como na passagem bíblica; “E a luz brilhou nas trevas, e as trevas não a compreenderam" (João 1,1).

\section{4 Últimas considerações}

A arte de Shakespeare permite interpretações em diversos níveis de profundidade. Conforme tentamos demonstrar, isso corrobora a sua qualidade mística que faz com que o leitor frequentemente sinta estar diante de algo maior que a simples apresentação literal de uma história bem contada. De fato, a jornada de que o leitor é convocado a participar é uma evolução espiritual.

Tentamos apontar paralelos entre a tradição mística da Kabbalah e algumas obras da maturidade de Shakespeare, na esperança de extrair as semelhanças no modo de interpretação dos textos sagrados e em certos simbolismos relativos à purificação espiritual.

Em que pese não se poder garantir que Shakespeare conhecesse a fundo os ensinamentos kabbalísticos, creio que podemos considerar, ao final deste artigo, que a influência do misticismo judaico está latente na obra do dramaturgo inglês, ainda que essa inspiração tenha se dado de maneira indireta, através das variadas correntes de pensamento místico que estavam acessíveis naquela época. É muito razoável concluir que os conhecimentos da ordem Rosacruz, bem como da arte medieval de Dante, por exemplo, tenham servido de base para que Shakespeare desenvolvesse sua técnica literária.

O conteúdo místico é parte fundamental da obra shakespeariana. Contudo, não se trata de exoterismo leviano e desmedido. Como pudemos ver, é preciso que tenhamos responsabilidade sobre o mistério das coisas. E quem quiser invocar esse poder e passar-se por servo da Criação, que esteja pronto para ser apontado em sua loucura. Ainda assim: melhor ser "louco"na companhia de Shakespeare e dos sábios kabbalistas, do que ser são em um mundo incapaz de sentir o doce perfume do verdadeiro Espírito.

\section{Referências}

ASHLAG, Yehuda. Shamati (I heard). Toronto, Canada: Laitman Kabbalah Publishers, 2010.

BAR YOCHAI, Shimon. The Zohar. New York: The Cabala Center International Inc., 2003. Vol. 1-23.

BENSION, Ariel. O Zohar. O livro do Esplendor. São Paulo: Polar. 2006.

LINGS, Marin. A arte Sagrada de Shakespeare. 0 mistério do homem e da obra. São Paulo: Polar, 2004

LURIA, Isaac. Portal das Reencarnações. Sha'ar Hguilgulim. Trad. e coment. Joseph Saltoun. São Paulo: Meron, 2014.

PAPUS. $A B C$ do Ocultismo. Trad. Sociedade das Ciências Antigas. São Paulo: Martins Fontes, 2003. (Coleção Arcanum).

PAPUS. O Tarô dos Boêmios. Trad. Sociedade das Ciências Antigas. São Paulo: Martins Fontes, 2003. (Coleção Arcanum).

SCHUON, Frithjof. The Transcendent unity of religions. New York: Harper and Row, 1984. SHAKESPEARE, William. The Illustrated Stratford - The Complete Works. London. Chancellor Press, 1982.

. Teatro completo: Comédias. Trad. Carlos Alberto Nunes. Rio de Janeiro: Agir. 2008. Teatro completo: Dramas. Trad. Carlos Alberto Nunes. Rio de Janeiro: Agir. 2008a. Teatro completo: Tragédias. Trad. Carlos Alberto Nunes. Rio de Janeiro: Agir. 2008b.

Recebido em 22/04/2016

Aceito em $30 / 07 / 2016$. 